\title{
Digital food activism: Values, expertise and modes of action
}

\author{
Karin Eli ${ }^{1}$, Tanja Schneider ${ }^{1}{ }^{2}$, Catherine Dolan ${ }^{3}$, and Stanley Ulijaszek ${ }^{1}$ \\ ${ }^{1}$ Institute of Social and Cultural Anthropology, University of Oxford \\ ${ }^{2}$ Institute of Sociology, University of St. Gallen \\ ${ }^{3}$ Department of Anthropology, SOAS, University of London
}

This is a pre-print of a forthcoming chapter, to be published in:

Schneider, Tanja, Karin Eli, Catherine Dolan, and Stanley Ulijaszek (eds.) Digital Food Activism. London: Routledge.

\section{Introduction}

In this chapter, we turn to the three case studies we explored in our 2013-2016 research project on how new information and communication technologies (ICTs) mediate novel forms of consumer activism and food governance. Each case study represents a different type of digital platform used in food activism: a mobile app, a wiki platform, and an online-centric activist organization. Case studies, by definition, do not provide an exhaustive review; for example, the case studies we selected do not address more diffuse activism through social media. Our aim, however, is not to review all types of digital food activism, but rather to capture diverse forms and potentials of digital food activism, and develop an analytic framework that can be applied to other cases in the field.

What do we mean by digital food activism? As we define it, digital food activism does not simply refer to food activism that occurs on digital media. Rather, it encompasses forms of food activism enabled and shaped by and through digital media platforms. Traditional food activism - for example, the work of alternative food networks (AFNs), such as Fair Trade, which focus on developing 'economic and cultural spaces' for the ethical production, distribution, and consumption of foods (Goodman and Goodman, 2009: 209) - also employs supportive digital elements, including websites, blogs, and social media presence to enhance their consumer base (Lekakis, 2014). Digital food activism, by contrast, occurs largely on and through digital media platforms, with the medium as a central part of the message. Digital platforms, such as social media, are then used to reimagine these traditional forms of AFN activism, creating new messages and activist publics - and, in the case of Fair Trade, implicating producers rather than consumers (see Lyon, this volume). The contrast between activism that occurs on digital media 
and activism shaped by digital media echoes Vegh's (2003) distinction between 'internet enhanced' and 'internet based' activism.

In each of our case studies, the origins, development, and implementation of the activist project were interwoven with a digital platform. These digital platforms, then, were conceptualized by the social entrepreneurs who developed them not as supporting consumer action, but as fostering and mediating both consumer and producer activism. The activism they facilitate, therefore, is 'internet based', rather than 'internet enhanced' (Vegh, 2003).

In comparing the forms of 'internet based' activism facilitated in the case studies, we therefore attend to the digital platforms that underlie them. 'Digital devices', as Ruppert et al (2013) argue, 'are simultaneously shaped by social worlds, and can in turn become agents that shape those worlds'. This co-constitutive shaping develops through the dynamic creation of logic, involving both humans and devices. According to Van Dijck and Poell (2013) the 'logic' of social media, while initially created by developers, is then 'distribute[d]' by platforms, adapted by users, integrated by institutions, and continuously updated by developers to influence and respond to user and industry dynamics. Through a complex of 'sociotechnical processes', human action and connection begin to incorporate social media logics. For example, in Bucher's (2013) analysis of Facebook, she finds that the concept and actualization of friendship on the platform inherently involves nonhuman actors and logics that become seamlessly integrated into the 'making' of human connections. Thus, to follow Sayes (2014), the digital platform is a mediator that continuously alters human relations, dynamically connecting human actors through nonhuman spaces and processes.

Drawing on actor-network theory, we suggest that digital platforms are not merely utilitarian objects, secondary to the principles of food activism. Previous research in sociology, geography, and critical food studies has challenged the imagined divisions between human and non-human in food networks, calling for a consideration of animals, crops, food products, and agricultural technologies as food network actors (Lockie, 2006; Morris \& Kirwan, 2011; Roe, 2006). We extend these critiques to the activist realm, and suggest that digital technologies play a formative role in emergent forms of food activism. Through a comparative analysis of three case studies, we pose a set of core questions: (1) who sets the agenda, and what values guide this agenda?; (2) what evidence counts, and who has the expertise to provide it?; and (3) what modes of action are employed, and through which constituencies (i.e., groups of supporters, users, or consumers)? Our answers suggest that it is in the interaction of activist entrepreneurs, consumer-citizens, producers, retailers, and digital platforms that new forms of food activism emerge.

\section{Methods}

Our analysis focuses on case studies of three activist organizations. We adapted our methods to each case study to reflect the types of organizations involved, the forms of data they produced, and the scale of their activist projects, as well as the level of access we could have to the workings of each.

Our mobile app case study focuses on Buycott. Buycott is a US-based barcode scanner app, with a global database that encompasses a range of retail products, including, predominantly, food. Buycott's stated mission is to enable consumers to 'vote with [their] wallet[s]' (Buycott, 2016). Unlike other barcode-scanner apps (such as Fooducate and the Good Guide), which offer authoritative information on the 'goodness' of food content - both nutritional and ethical Buycott engages in a different type of knowledge production, one that positions the app itself as 
a neutral platform. App users generate activist campaigns, and provide both data and judgment; other users join those campaigns. When a user scans a product with Buycott, the app alerts the user to conflicts between the campaigns the user has joined and the politics of the company behind the product (see also Eli et al., 2016). In our analysis of Buycott, we focused on consumer, app developer, and news media framings of Buycott's two largest campaigns (Eli et al., 2016). To obtain additional information about the operations of Buycott, Inc., the company behind the app, we conducted a brief Skype interview with company founder Ivan Pardo in February 2017.

Our wiki platform case study focuses on a Central European organization we call by the pseudonym HowToBuyWiki. HowToBuyWiki is a non-profit organization dedicated to the development of an emerging, open-source internet platform which, as the members describe it, is designed to enable 'conscious consumption' through promoting 'product transparency'. With the wiki platform focused on the structuring and sharing of comparative information about products, as provided by wiki editors and users, HowToBuyWiki engages in a data-centric form of consciousness-raising among consumers. Founded in 2006 by a group of friends and registered as a charitable organization, HowToBuyWiki advocates a 'civil society' concept that emphasises their organization's independence from governmental, commercial, and thirdsector institutions. Our case study of HowToBuyWiki relied on thematic analysis of interviews and documents provided by the organization's members, alongside our own exploration of the wiki platform as (non-contributing) users. From May to October 2013, we interviewed all six active members of HowToBuyWiki. In addition, HowToBuyWiki's core members provided us with meeting minutes, the HowToBuyWiki constitution, and other related documents, which we have also incorporated into the analysis (see Eli et al., 2015). Given the access we had to this small organization's internal memoranda and behind-the-scenes negotiations, we have chosen to use a pseudonym to protect the confidentiality of the members.

Our case study of an online-centric consumer advocacy organization focuses on foodwatch. Foodwatch describes itself as 'an independent, non-profit organisation that exposes foodindustry practices that are not in the interests of consumers' (foodwatch, 2016). Using a number of digital media tools, including e-newsletters, Twitter, and Facebook, foodwatch campaigns for a number of targeted causes by appealing for consumer support in the form of e-letter writing, donations, and membership. The main communication tools foodwatch employs are its website and its weekly e-newsletter, which is sent out to subscribers via email, and can either be read on or downloaded from the foodwatch website. Our case study is based on a thematic analysis of 50 e-newsletters that foodwatch published during 2013 (see Schneider et al. [under review]).

The analysis that follows draws on our detailed investigation of these three case studies (Eli et al., 2015; Eli et al., 2016; Schneider et al., under review), to identify key features that define digital food activism.

Who sets the agenda, and guided by what values?

All three digital platforms represent the visions of activist entrepreneurs, who continue to lead their respective organizations. The organizations' agendas, however, are set by different actors. While Buycott developer Ivan Pardo initially branded the app as supporting particular agendas - namely, the labelling of genetically modified foods, and the avoidance of prominent Republican Party funders Koch Industries - he currently positions the app as a neutral space, to be shaped by app users. Accordingly, Buycott features multiple, and sometimes conflicting, activist agendas as defined by user-generated campaigns. Along similar lines, while HowToBuyWiki's members created their organization to support 'conscious consumption', with 
particular attention to sustainability and transparency, they developed their wiki platform as a neutral space, where agendas would be set by users (whom they call 'wiki editors'). In contrast, foodwatch, which is led by former Greenpeace Germany director Thilo Bode, is the only organization of the three that sets its agenda rather than acting as a platform for agendas set by users. Not incidentally, of the three, it is also the only organization that has a geographic presence, with offices in Foodwatch's three sites - Berlin, Amsterdam, and Paris.

While Buycott and HowToBuyWiki emphasize user-led agenda setting, the forms of agenda setting they enable are structured by the organizations' use of digital platforms for interacting with their users and each organizations' core values. Buycott's core values are centred in promoting corporate transparency, exposing the political connections hidden in retail products, and enabling consumers to use the market as a political arena, with boycott and buycott action conceptualized as impacting on corporations and policymakers. As such, the user-led agendas set on and through Buycott involve, by design, the unveiling of corporate relationships and of connections between corporations and political causes. For example, Buycott's GMO labelling campaign highlights that, in the US, Monsanto has financed advertising to oppose propositions for the mandatory labelling of genetically modified foods. ${ }^{1}$ When creating a campaign, users are prompted to enter the names of companies to oppose and companies to support, based on their connection to the cause; when users scan a product, a corporate kinship chart is generated to reveal connections between the product, its manufacturer, other companies, and parent companies. On HowToBuyWiki's platform, the organization's shaping of agenda-setting is equally pronounced. User-led agendas must follow HowToBuyWiki's inbuilt construction of product transparency as the organizing principle for data entry and presentation.

HowToBuyWiki's core values are product transparency, exposing the attributes of products (that are often left off labels), enabling informed comparison within product categories, facilitating conscious consumption practices, and changing power relations in the market. In designing the wiki platform, HowToBuyWiki reflects these values through constructing wiki pages based on comparative tables divided by product category, wherein products are compared across several attributes; the attributes assigned to the chocolate table, for example, include brand, ingredients, allergens, and organic labelling, among others (see Eli et al., 2015). In the case of Foodwatch, the core values guiding the organization's agenda setting are food industry transparency, truth in advertising; focus on food safety, health and food security, and linking local and global food issues. Notably, unlike Buycott and HowToBuyWiki, foodwatch has core values that do not directly involve everyday consumer action in the form of consumption choices. Instead, these values lend themselves to foodwatch's approach to consumer action: calling for letter-writing campaigns.

\footnotetext{
${ }^{1}$ http://buycott.com/campaign/companies/211/pro-gmo-or-pro-right-to-know (accessed 7 March 2017).
} 
Table 1: The organizations' agenda-setting and values in comparison

\begin{tabular}{|l|l|l|l|}
\hline Organizers & Buycott & HowToBuyWiki & Foodwatch \\
\hline Agenda & $\begin{array}{l}\text { App developer Ivan } \\
\text { Pardo }\end{array}$ & $\begin{array}{l}\text { The HowToBuyWiki } \\
\text { organization members }\end{array}$ & $\begin{array}{l}\text { Thilo Bode and the } \\
\text { Foodwatch } \\
\text { organization }\end{array}$ \\
\hline Core values & $\begin{array}{l}\text { Set by campaign } \\
\text { organizers (and } \\
\text { moderated by } \\
\text { Buycott) ('users') }\end{array}$ & $\begin{array}{l}\text { Set by wiki editors } \\
\text { ('users') }\end{array}$ & $\begin{array}{l}\text { Set by Foodwatch (not } \\
\text { user-driven) }\end{array}$ \\
& $\begin{array}{l}\text { Corporate } \\
\text { transparency; } \\
\text { exposing the political } \\
\text { connections hidden in } \\
\text { retail products; } \\
\text { enabling consumers to } \\
\text { use the market as a } \\
\text { political arena }\end{array}$ & $\begin{array}{l}\text { axposing the } \\
\text { attributes of products } \\
\text { (that are often left off } \\
\text { labels) and enabling } \\
\text { informed comparison } \\
\text { within product } \\
\text { categories; facilitating } \\
\text { conscious } \\
\text { consumption } \\
\text { practices; } \\
\text { changing power } \\
\text { relations in the market }\end{array}$ & $\begin{array}{l}\text { truth in advertising; } \\
\text { focus on food safety, } \\
\text { health and food } \\
\text { security; } \\
\text { linking local and } \\
\text { global food issues }\end{array}$ \\
\hline
\end{tabular}

As Table 1 shows, while all three organizations aim to promote transparency, their actions are directed at different aspects of the food landscape - corporations, consumer products, and the food industry. These differences in focus, then, link with the organizations' differing conceptualizations of who sets their agendas: whereas Buycott and HowToBuyWiki focus on action at the retail end and conceptualize consumers as setting the agenda, foodwatch focuses on action at the often-inaccessible macro-level of the food industry and positions itself as the agenda-setter.

What evidence counts, and who has the expertise to provide it?

Data are at the heart of all three activist platforms - but the types of evidence that count and the expertise that supports it are diverse. Buycott relies on data provided, mostly, by campaign organizers and subscribers. On the Buycott website, each campaign has a dedicated page, with a list of companies to be boycotted or buycotted; there, links are provided to support some claims, though the quality of those sources varies widely. Expertise is crowdsourced; names of expert scientists or activists are not invoked, and the reliability of data and claims depends on the collective of Buycott users. Crowdsourced data are also central to the HowToBuyWiki project, although, in practice, much of the data currently on the wiki platform were provided by the HowToBuyWiki members themselves, because the project had not reached critical mass at the time of writing. Evidence is dependent on corporations, as HowToBuyWiki data are gleaned from product labels, websites, and information provided by producers; HowToBuyWiki members emphasize that wiki users are free to debate the reliability of data on the wiki page of any product category, where multiple contesting sources may exist. HowToBuyWiki's project is

\footnotetext{
${ }^{2}$ No information on how campaign topics are chosen is available on the foodwatch website.
} 
supported by an expert advisory board, which includes journalists, consumer advocates, and policymakers, whom HowToBuyWiki invited to consult and raise the profile of the organization (while leaving agenda-setting to wiki users); the advisory board, however, is not involved in data-related matters. Of the three organizations, Foodwatch alone relies on its own expertise. Foodwatch provides the data to support its campaigns, and invokes the organization's own status as evidence for the reliability of claims. Few references are made to named external experts, data are not crowdsourced, and - unlike Buycott and HowToBuyWiki - foodwatch does not facilitate consumer feedback on or dialogue about the data provided, although followers of foodwatch on social media (e.g., on Facebook) occasionally discuss foodwatch campaigns on the organization's pages.

Table 2: The organizations' forms of evidence and expertise in comparison

\begin{tabular}{|c|c|c|c|}
\hline & Buycott & HowToBuyWiki & Foodwatch \\
\hline Data & $\begin{array}{l}\text { Mostly provided by } \\
\text { campaign organizers } \\
\text { and subscribers }\end{array}$ & $\begin{array}{l}\text { Crowdsourced, in } \\
\text { principle (mostly } \\
\text { provided by } \\
\text { HowToBuyWiki, in } \\
\text { practice) }\end{array}$ & $\begin{array}{l}\text { Provided by } \\
\text { Foodwatch; mostly } \\
\text { secondary data, e.g., } \\
\text { published reports } \\
\text { (although, in certain } \\
\text { cases, foodwatch has } \\
\text { funded research to } \\
\text { obtain data). }\end{array}$ \\
\hline Evidence & $\begin{array}{l}\text { On the Buycott } \\
\text { website, links are } \\
\text { provided to support } \\
\text { some claims } \\
\text { implicating companies } \\
\text { in campaigns }\end{array}$ & $\begin{array}{l}\text { Product data are } \\
\text { gleaned from labels, } \\
\text { websites, and } \\
\text { producer information; } \\
\text { the organization } \\
\text { suggests that sources } \\
\text { be provided to support } \\
\text { the information } \\
\text { editors add to wiki } \\
\text { pages; reliability can } \\
\text { be debated on wiki } \\
\text { pages }\end{array}$ & $\begin{array}{l}\text { Claims rely on the } \\
\text { organization's own } \\
\text { expertise, research, } \\
\text { and some publicly } \\
\text { available documents. }\end{array}$ \\
\hline Expertise & Crowdsourced & $\begin{array}{l}\text { Crowdsourced; } \\
\text { advisory board } \\
\text { (journalists, consumer } \\
\text { advocates, and } \\
\text { policymakers) to } \\
\text { provide legitimacy }\end{array}$ & Foodwatch \\
\hline
\end{tabular}

Table 2 shows the different forms of evidence and expertise that each organization emphasizes and claims. The crowdsourced data models employed by both Buycott and HowToBuyWiki eschew a reliance on named, authoritative experts. Both organizations cultivate an image of collective grassroots action driven by pseudonymous concerned citizens, identified only by their screen-names, who pool their knowledge to mobilize for product and corporate transparency. While HowToBuyWiki has assembled an expert advisory board, it draws on their expertise to lend legitimacy to the project, but not to legitimize wiki editors' claims about products or industry. In contrast, the data model employed by foodwatch - in which data are presented as persuasive evidence to generate public support for the organization's campaigns - calls for the 
claiming of authoritative expertise. Thus, whereas Buycott and HowToBuyWiki create (the appearance of) a flattened hierarchy of political participation through crowdsourcing data, foodwatch maintains, and indeed reinforces, hierarchies of political voice and expertise through presenting data to consumers, rather than involving consumers in data generation and discussion.

What modes of action are employed, and through which constituencies?

Each of the organizations envisions a different mode of consumer action. Buycott concentrates on users' everyday shopping practices. Guided by the motto 'voting with your wallet', the mode of action promoted on Buycott is consumer boycott or 'buycott' of retail products. As framed by Buycott, this action is generated by users, who set campaigns and provide data on companies, facilitated by the app. The active constituency for this action is comprised of Buycott users who subscribe to a given campaign; action is predicated on ownership of a smartphone or tablet, and on literacy with the use of mobile apps.

While HowToBuyWiki aims to foster 'conscious consumption', it envisions a mode of action that involves fostering discussion and corporate accountability through the wiki site. As the members of HowToBuyWiki frame it, their project's main goal is to change market dynamics, giving more weight to the voices of consumers; a wiki platform, they argue, provides a space where consumers can challenge corporations. The action they envision is facilitated by the platform and generated by wiki editors, who create wiki pages for products, with tables that compare the attributes of similar products from various brands. However, at the time of the study, the platform, which requires knowledge of wiki programming code, was difficult to edit. In response to an earlier draft of this manuscript, a leading member of HowToBuyWiki has informed us that, in the intervening years, the organization has taken steps to simplify the editing process, but that certain elements of the wiki editing processes, such as making product lists on the wiki platform, remain difficult. HowToBuyWiki's primary constituency is, therefore, wiki editors, although the organization also imagines the general public - or 'passive' readers as acting on the information generated on and through the site.

Unlike the everyday consumption or dialogue between consumers and producers advocated by Buycott and HowToBuyWiki, foodwatch employs online petitions, email writing campaigns, pressure on public figures and decision makers, and public shaming of companies as its mode of influence. This action is generated and directed by foodwatch, which mobilizes its active constituency of subscribers and the news media to facilitate its campaigns. Compared to the other two organizations, the action facilitated by foodwatch requires only basic technological infrastructure and literacy, as it is predicated on signing petitions via email or social media accounts. Foodwatch's use of the internet for campaigning, or 'e-mobilization', allows the organization to 'capitalize on its potential for recruitment, fund-raising, organizational flexibility and efficiency' (Chadwick, 2006: 115).

Modes of action are also influenced by legal status and funding; here, the three organizations show considerable diversity. Of the three organizations, Buycott, is the only one that was founded and is operating as a corporation. Ivan Pardo, the company's founder, explained that the decision to register Buycott, Inc. as a company rather than as a non-profit organization was due to the ease of incorporating as a company in California (personal communication, 22.2.17). Buycott's website provides little information on the company's core team and no information about its financial situation. At the time of writing, Internet searches for information on Buycott's stock volume, shareholders, annual report or funding sources have not yielded any data. Initial news media reportage on Buycott stated that Pardo, a digital entrepreneur, had 
originally bootstrapped ${ }^{3}$ the development of the app and received help from two friends who 'pitched in to promote the app' (O'Connor, 2013), although their possible financial contribution was not mentioned. Since the app is free to download, no revenue is made from the sale of the app directly. However, the app now includes a revenue-generating upgrade: an in-app recommendation for alternative products, with links to online shops where these products can be purchased. While the app and the Buycott website are both updated regularly, it is unclear how many staff are involved in the technical and financial operations related to the app. In our interview, Pardo explained that his vision for Buycott focused on growing it as an activist platform that enables users to discover quickly relevant and actionable information. He emphasized that he was not motivated by achieving high financial returns on investment, and that he was content with Buycott generating just enough income for him 'to pay the bills', thereby allowing him to continue to develop the platform full time. When asked about Buycott's investors' expectations, Pardo admitted that some would prefer the company to generate more profit, but that most investors were relaxed about revenue as their investments were ideologically, rather than financially, motivated.

In contrast, HowToBuyWiki, a registered society in its country of origin and as such a non-profit organziation, includes financial information on its publicly accessed wiki platform.

HowToBuyWiki explains in one sub-section of the wiki platform that membership fees and donations assist with financing the costs associated with server rental and, ideally, could be used for future employment of administrative staff tasked to run the platform. Indeed, currently, HowToBuyWiki's main way of sustaining the platform and group's activities financially are membership fees paid by the HowToBuyWiki organization members and donations. From our conversations with HowToBuyWiki's members and analysis of the documents they shared with us, we know that the organization has applied for funding from independent private foundations that support civil society efforts and visions; to date, these applications have been unsuccessful. The lack of funding has slowed the project's progress, as the organization's members are only able to develop the platform on an uncompensated, part-time basis, with no funds to hire external support.

Foodwatch and its team of 13 full-time and five part-time members are financed by support on a much larger scale, primarily through membership fees and donations. In comparison to Buycott, foodwatch, which is registered in Germany as a charitable organization, provides detailed information about the organization's finances on its website. On the foodwatch German language website, clicking on 'About foodwatch' and then on the subsection submenu 'Finances and Transparency'4 leads to a page that describes foodwatch as striving for independence, and explains that foodwatch accepts neither state funding nor donations by the food industry or larger companies in the food retail sector. To achieve this, foodwatch states that it checks whether donors of sums greater than 500 Euro have any ties to these sectors. Moreover, donors of sums greater than 5000 Euro are listed by name on the organization's website. Foodwatch also provides details of its earnings and expenditures on its website (the latest available are for 2014, with comparisons to 2012 and 2013). Foodwatch's financial transparency echoes its broader values and aims to achieve more transparency in the food industry. The organization is part of 'Initiative Transparente Zivilgesellschaft' (Initiative transparent civil society) organized

\footnotetext{
3 To bootstrap is a financial/investment term that specifies that entrepreneurs start a company by drawing on their personal finances or the operating revenues of the new company, rather than seeking a bank loan or other forms of investment.

${ }^{4}$ For detailed information, see http://www.foodwatch.org/de/ueber-foodwatch/finanzen-transparenz/ (in German, accessed 2 August 2016).
} 
by Transparency International in Germany that stipulates that each civil society organization should disclose ten items/facts such as its constitution, the names of its key decision makers, and personnel structure, as well as information about sources and application of funds to the public. ${ }^{5}$ Foodwatch adheres to these requirements and, in addition, offers information about the organization's financial funding process as a 'start-up-NGO' in 2002.

Table 3: The organizations' modes of action and active constituencies in comparison

\begin{tabular}{|c|c|c|c|}
\hline & Buycott & HowToBuyWiki & Foodwatch \\
\hline Mode of action & $\begin{array}{l}\text { 'Voting with your } \\
\text { wallet': consumer } \\
\text { boycott/buycott of } \\
\text { retail products; action } \\
\text { generated by users } \\
\text { and facilitated by app }\end{array}$ & $\begin{array}{l}\text { Fostering discussion } \\
\text { and corporate } \\
\text { accountability through } \\
\text { wiki site; action } \\
\text { generated by users } \\
\text { and facilitated by wiki }\end{array}$ & $\begin{array}{l}\text { Online petitions, email } \\
\text { writing campaigns and } \\
\text { public shaming of } \\
\text { companies; } \\
\text { action generated by } \\
\text { Foodwatch, which } \\
\text { mobilizes subscribers } \\
\text { and media }\end{array}$ \\
\hline Active constituency & $\begin{array}{l}\text { Campaign creators and } \\
\text { subscribers; } \\
\text { subscriptions are } \\
\text { linked to users' email, } \\
\text { Twitter, or Facebook } \\
\text { accounts (largest } \\
\text { campaign as of } 13 \\
\text { February 2017: 'Pro- } \\
\text { GMO or Pro-Right to } \\
\text { Know?'; } 523,193 \\
\text { subscribers) }\end{array}$ & $\begin{array}{l}\text { Wiki editors, as well as } \\
\text { the general public } \\
\text { (wiki readers) }\end{array}$ & $\begin{array}{l}\text { Foodwatch members, } \\
\text { newsletter } \\
\text { subscribers, and } \\
\text { Facebook followers } \\
\text { (number of 'likes' on } \\
\text { official Facebook page, } \\
\text { as of } 13 \text { February } \\
2017: 363,893)^{7}\end{array}$ \\
\hline Legal status & $\begin{array}{l}\text { Incorporated, } \\
\text { domestic stock } \\
\text { (California, USA) }\end{array}$ & $\begin{array}{l}\text { Registered as a } \\
\text { charitable } \\
\text { organization (in } \\
\text { country of origin) }\end{array}$ & $\begin{array}{l}\text { Registered as a } \\
\text { charitable } \\
\text { organization } \\
\text { (Germany) }\end{array}$ \\
\hline Financing & $\begin{array}{l}\text { Bootstrapping before } \\
\text { app launch; supported } \\
\text { by a number of } \\
\text { investors }^{8}\end{array}$ & $\begin{array}{l}\text { Membership fees paid } \\
\text { by the core committee; } \\
\text { donations from family } \\
\text { and friends; } \\
\text { (unsuccessful) } \\
\text { applications to civil } \\
\text { society organizations }\end{array}$ & $\begin{array}{l}\text { Membership fees and } \\
\text { private donations }\end{array}$ \\
\hline
\end{tabular}

5 For more information about Foodwatch's participation in the initiative, see http://www.foodwatch.org/de/ueber-foodwatch/finanzen-transparenz/transparenz-initiative/ (in German, accessed 2 August 2016). For more information about the initiative for transparent civil society, see https://www.transparency.de/Initiative-Transparente-Zivilg.1612.0.html (in German, accessed 2 August 2016). Some information is accessible in English, too: https://www.transparency.de/English.1222.0.html (accessed, 2 August 2016).

${ }^{6}$ https://buycott.com/campaign/211/pro-gmo-or-pro-right-to-know (accessed 13 February 2017)

7 https://www.facebook.com/foodwatch/ (accessed 13 February 2017)

${ }^{8}$ This information is based on personal communication with Ivan Pardo, Buycott's founder (22 February 2017). 
While both Buycott and foodwatch use campaigning as their mode of action, as Table 3 shows, the campaigning these organizations facilitate takes either a grassroots or a top-down approach, in concert with each organization's framing of constituency and organizational identity (as forprofit or charity). Structured as a 'traditional' non-profit, foodwatch has the organizational structure and the funding to operate as an expert organization that generates campaigns. By contrast, Buycott's reliance on user-generated data dovetails with its incorporated status, which opens its potential for third-party revenue, for example, via the distribution of user reviews to social media sites (Buycott, 2015) and by referring users to online stores where 'alternative' products can be purchased (personal communication, 22.2.2017). In our view, this highlights the extent to which some forms of digital food activism have the potential to become an economic activity for those who set up, develop and own platform and data. HowToBuyWiki, on the other hand, conceptualizes data as generated by wiki editors rather than by individually identifiable users, and, as a registered charity, cannot employ user-generated data to grow the company.

\section{Discussion and implications}

While digital food activism shares much with alternative food networks - in foci and in concepts of activism as fostered through 'conscious' consumption and non-consumption - it weaves together digital platforms with activist values and modes of action, such that technology and values are bound together. In each of the case studies, the activist systems involve similar actors, yet the vectors of action and influence are different. These vectors reflect not only the core values of each activist organization, but also an imagining and interpretation of values and preferred action that is closely connected with each organization's digital platform. The comparison of case studies therefore reveals the plurality of digital food activism - a plurality closely linked to the platforms used. The comparison also reveals the limits of these platforms, whose use is always-already constrained by technological literacy and infrastructure.

In the logic of interaction configured by Buycott (figure 1), the app itself - and the organization that developed it - are positioned as mediators. While the organization itself mobilizes media support and empowers consumers, it does not directly leverage this mobilization to influence corporations and policymakers. Rather, as members of the general public become Buycott subscribers, and as subscribers reinforce or start campaigns on the mobile app, they act through Buycott to mobilize for political change, with performances of product boycotts and buycotts online (and presumably also offline). 


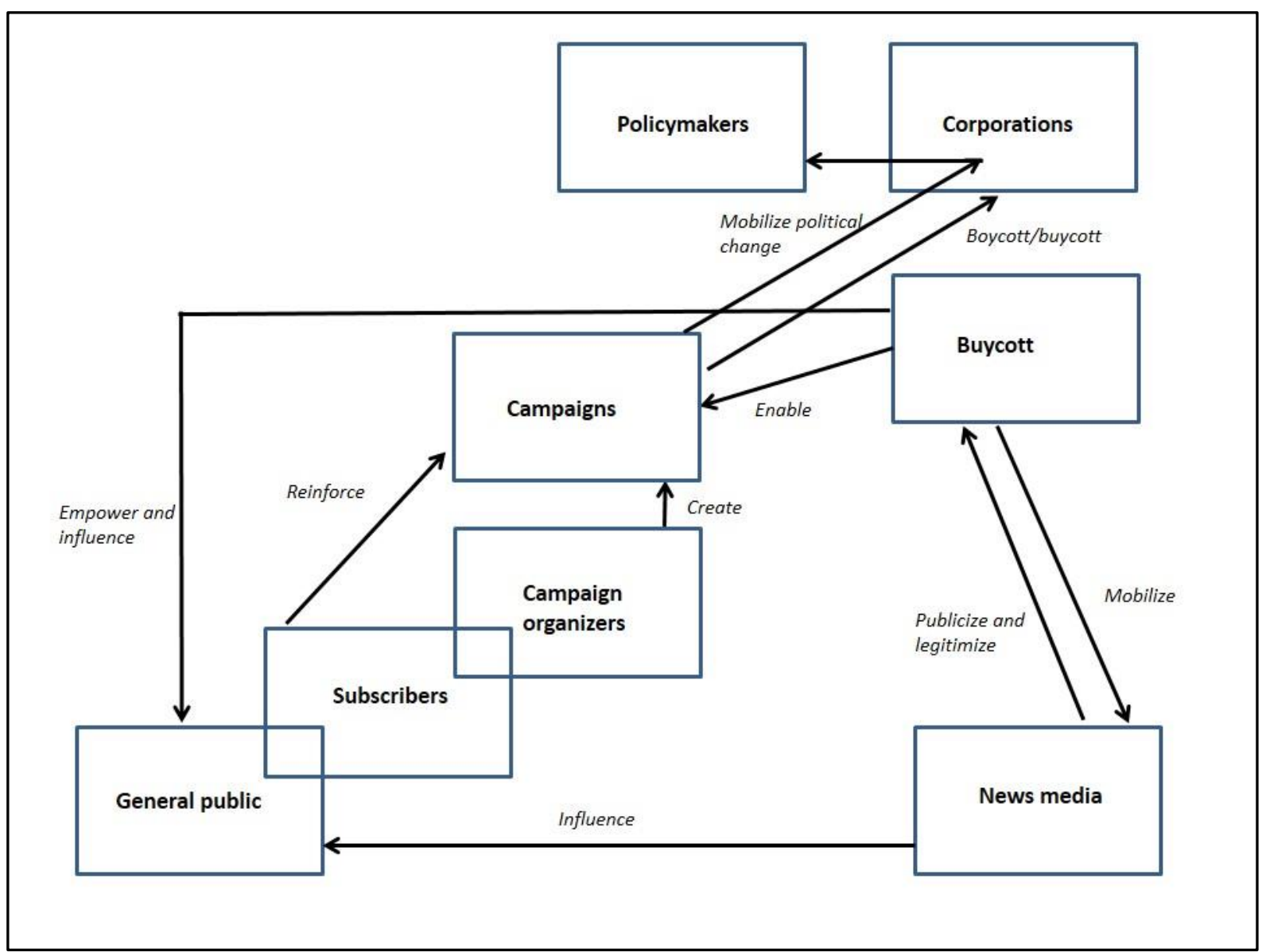

Figure 1: Buycott's logic of interaction

Similarly, in the logic of interaction envisioned by HowToBuyWiki (figure 2), as members of the general public become 'conscious consumers', that is, wiki editors or readers, they are able to use the wiki site to pressure corporations (or as HowToBuyWiki phrases it, producers). However, in constructing a fairly difficult-to-edit wiki platform, HowToBuyWiki also configured a more central role for itself, with members of the organization acting as wiki editors. In addition, unlike Buycott, which builds its legitimacy through news media coverage and numbers of subscribers, HowToBuyWiki seeks to legitimize itself as an organization through the more traditional means of convening an expert advisory board, reinforcing the centrality of the organization's core membership in defining and sustaining its project. 


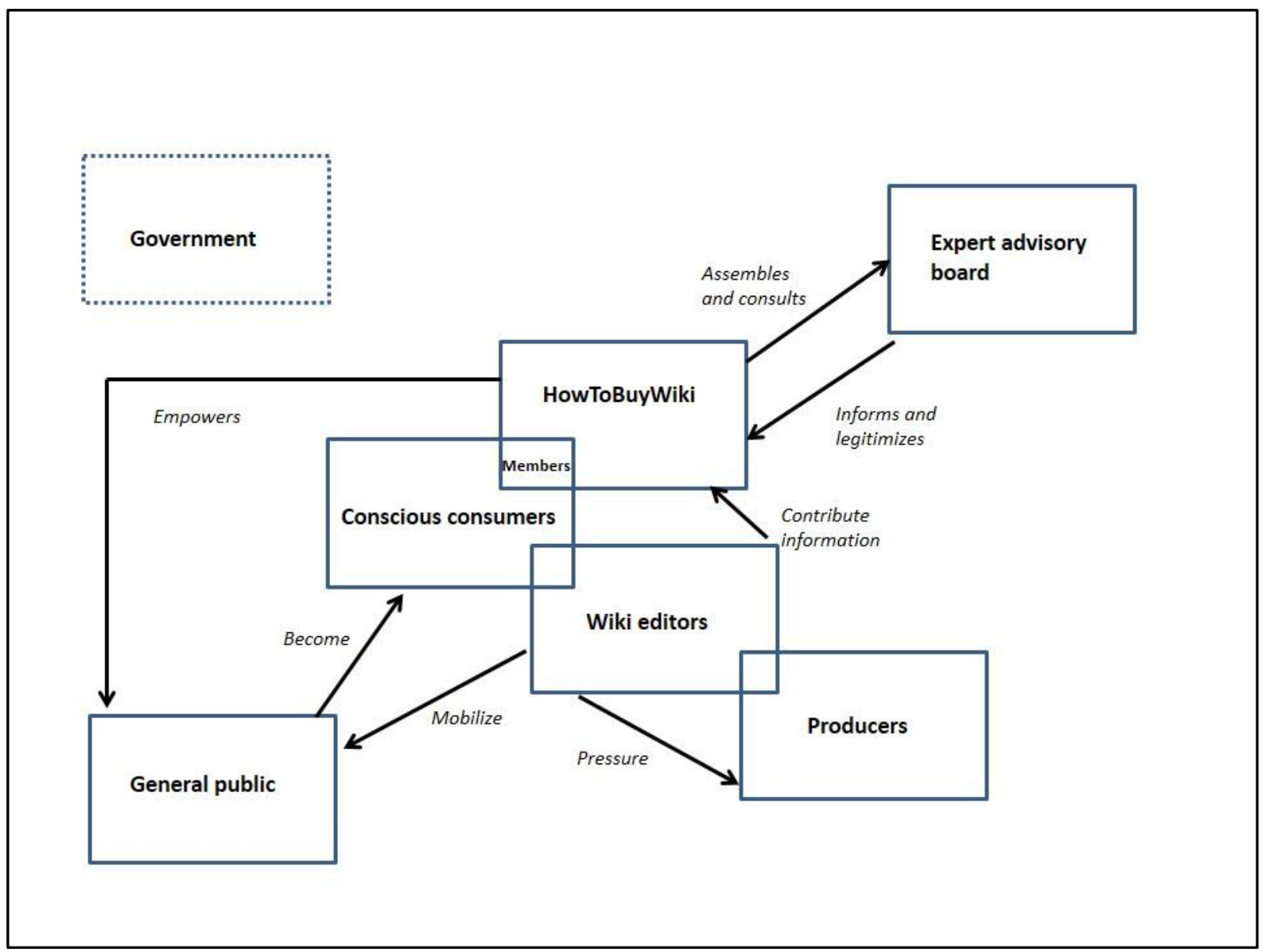

Figure 2: HowToBuyWiki's logic of interaction

Unlike Buycott and HowToBuyWiki, foodwatch places itself as the main agent in its logic of interaction (figure 3). The organization mobilizes subscribers and news media alike to legitimize its project; through media coverage and numbers of subscribers, foodwatch gains the necessary authority to protest and expose corporations, and petition and accuse government ministers of collusion with a food industry that does not respect consumer interests and human welfare. Although foodwatch positions these actions as representing the interests of the general public, consumers act through foodwatch only in adding their names to prewritten campaigns, and do not participate in its agenda setting; rather, their role is to empower this central organization as a sole agent. 


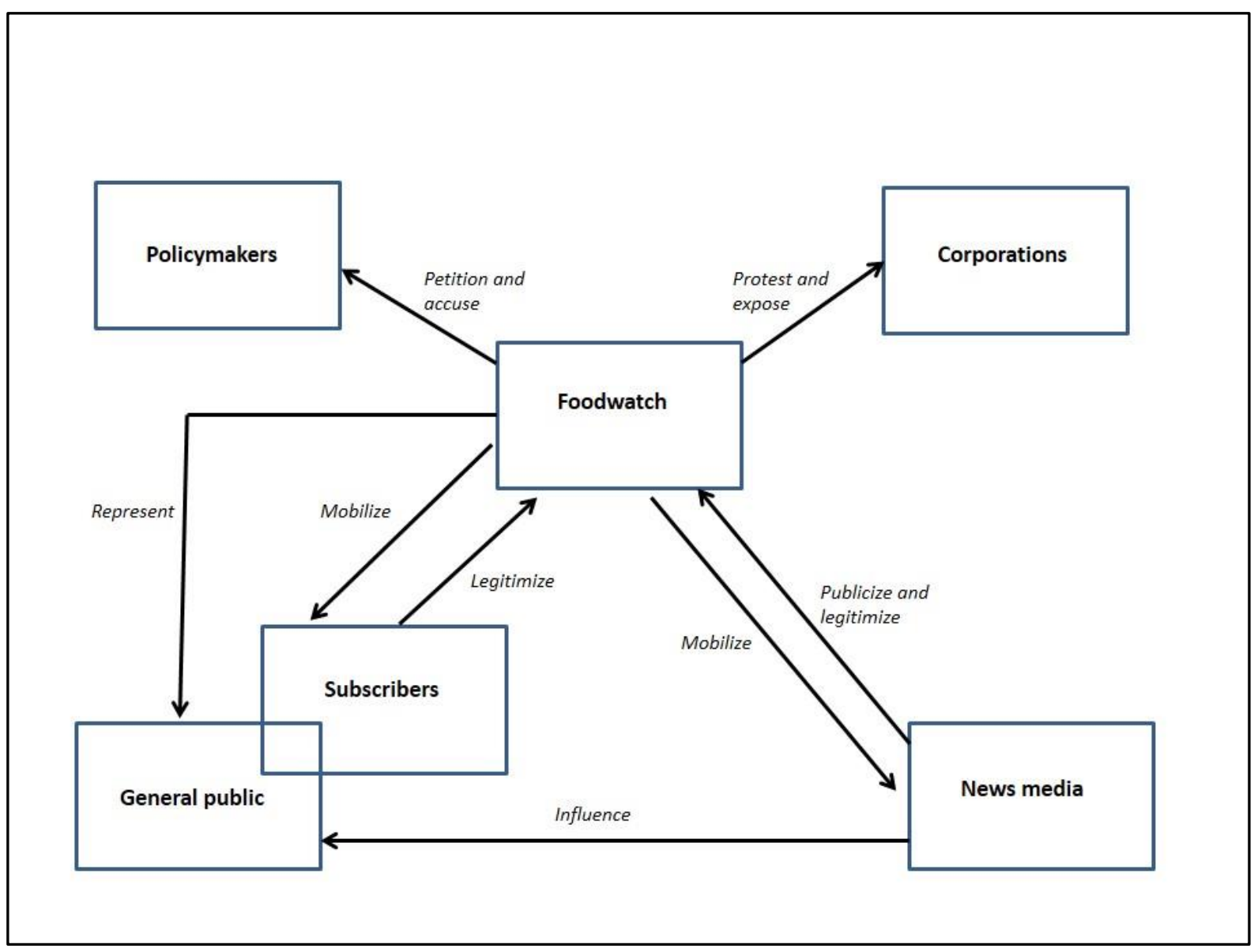

Figure 3: Foodwatch's logic of interaction

While food activism, as defined by Siniscalchi and Counihan (2014: 3), refers to 'efforts by people to change the food system across the globe by modifying how they produce, distribute, and/or consume food', our concept of digital food activism extends beyond immediate concerns with the food system, to encompass activist projects where food is a means to broader political action. Based on our case studies, we suggest that at the core of digital food activism is the changing of market relations. Sinischalchi and Counihan (2014) observe that

food activists often try to exploit the community dimension [of the economy] to affect the market dimension, for example, by creating farmer's markets or fair trade regimes to link producers and consumers in personal relationships that accrue economic benefits to both (p. 10).

All three organizations appeal to this 'community dimension'. Buycott and HowToBuyWiki encourage users to upload information about products and companies for the benefit of other users, while foodwatch mobilizes consumers to share foodwatch's insights with members of their social networks, and to partake in collective email petition writing. In all three cases the community dimension is used to develop consumer publics that form around products and issues, with the aim of achieving greater transparency, fairness, and justice through getting closer to food's origin (cf. Schneider et al., under review). Entangled in these ambitions is a commitment to affect markets. By shifting flows of information, Buycott and HowToBuyWiki seek to shift and redirect flows of money to alternative food (and other product) networks. In the case of foodwatch, providing and promoting alternative information on products and companies is envisioned as affecting the governance of markets and marketing. 
In developing food issue publics, these three organizations also generate activist or business models that could, in theory, allow for growth. While the participatory 'community dimension' is central to the missions of these organizations, community formation can also be viewed as a means of 'outsourcing' costs through increasing the numbers of users who contribute to the platform's content or act as lay ambassadors of the organization, thus providing their knowledge, expertise, or marketing support for free. This configuration positions consumers not simply as activists but as producers - or 'prosumers'9 (Gabriel and Lang, 2015) - a process characteristic of the sharing and platform economy. ${ }^{10}$

While Buycott, HowToBuyWiki, and foodwatch all privilege transparency as an organizing value, we found that the organizations locate transparency in different nodes of the production chain. While foodwatch calls for transparency in marketing, production processes, and political lobbying, HowToBuyWiki emphasizes ingredients and environmental impact, and Buycott focuses on exposing corporate ownership. These definitions of transparency inform, and are also shaped by, the platforms themselves; for example, ingredients and sustainability feature centrally as attributes in HowToBuyWiki's comparative tables, while corporate kinship charts are key to Buycott's visualizing of campaigns. Thus, while certain aspects of a food product or its manufacturer are rendered visible through these platforms, other potential aspects remain more obscure. We suggest, therefore, that in the realms of food production, distribution, and consumption, the definition of transparency is wide-ranging and organizations aiming to make food-related processes more transparent make choices that (knowingly or unknowingly) contribute to qualifying what food transparency is. To make this organizational qualification process visible, the organizations we studied might regularly disclose how they decide to focus on certain aspects of food production, distribution, and consumption. HowToBuyWiki, for example, might promote further transparency on the wiki platform by stating on each wiki page (and encouraging wiki editors to do so, as well) why particular product categories and attributes were chosen. Likewise, foodwatch might offer information on how they select the food issues highlighted in their campaigns, amongst a range of possible topics. Buycott might explain why corporate ownership is key to transparency, where food-related issues and campaigns are concerned.11

To understand the implications of digital platforms, we must address their modus operandi the productive logics that structure them, and that, in turn, enable them to structure human action (Ruppert et al., 2013). Such 'reverse engineering', to use Fox's (2015) phrase, unveils the micropolitics and possibilities that inhere in digital platforms. In the realm of digitally-enabled activism, other scholars have called attention to new forms and concepts of action generated by

\footnotetext{
${ }^{9}$ Gabriel and Lang (2015: xi) explain that '"prosumer"' is 'a word combining "producer" and "consumer" coined by futurologist Alvin Toffler to denote that the work process is being incorporated into the consumption process and vice versa'.

${ }^{10}$ While all three organizations have potential for development through crowdsourced consumer action, the growth trajectories they have followed diverge considerably. Reasons may include differences between the organizations' geographic foci, legal status, news media and public engagement, and the accessibility of their user interfaces, among others.

${ }^{11}$ Another aspect of transparency is organizational. In attending to the organizations' legal statuses and funding statements, it becomes apparent that the provision of such information, rather than being built into the platforms, is entirely dependent on the organizations' own disclosure statements. Of note, Buycott - the only organization among the three not to be registered as a charity - has not been challenged by users to disclose its financial information, despite the fact that the Buycott app targets user concerns over corporate transparency, suggesting that the concept of transparency may carry different value judgments when a digital, crowdsourced activism platform is involved.
} 
and through digital platforms - and, in particular, social media. In an analysis of activism on Facebook, Langlois et al (2009) have suggested that 'online platforms' define new 'issue publics', through offering a means of association and action to individuals who would not have connected otherwise. Bennett and Segerberg (2012) have argued that digital platforms also provide a new activist logic, with digitally-enabled activism based in 'connective', rather than collective action - a logic that transposes activism from centrally directed, organized action to diffuse, individual sharing of data.

As the analysis we have presented here has shown, differences between digital food activism platforms reflect different activist logics. These logics are, in turn, reproduced through the digital platforms themselves, and the potentialities for action that they offer, enable, and direct. The digital platforms, then, become part of the activist landscape, revealing and structuring diverse (and at times divergent) pathways to digital food activism.

\section{$\underline{\text { Acknowledgments }}$}

We would like to thank HowToBuyWiki's members and Buycott Inc. founder Ivan Pardo for generously sharing information about their organizations. Thanks also go out to Amy K. McLennan and Javier Lezaun, who co-authored two of the case study papers that stemmed from this project. This chapter is based on research funded by the Oxford Martin Programme on the Future of Food, and we are thankful for the Oxford Martin School's generous support.

\section{$\underline{\text { References }}$}

Bennett, W. L., \& Segerberg, A. (2012). The logic of connective action: Digital media and the personalization of contentious politics. Information, Communication \& Society, 15(5), 739-768.

Bucher, T. (2013). The Friendship Assemblage Investigating Programmed Sociality on Facebook. Television \& New Media, 14(6), 479-493.

Buycott. (2015). Terms and conditions. <https://www.buycott.com/terms $>$ (accessed 14 February 2017).

Buycott. (2016). Vote with your wallet. < https://www.buycott.com/> (accessed 8 August 2016).

Chadwick, A (2006) Internet Politics: States, Citizens, and New Communication Technologies. Oxford: Oxford University Press.

Eli, K., McLennan, A. K., \& Schneider, T. (2015). Configuring relations of care in an online consumer protection organization. In E.-J. Abbots, A. Lavis and L. Attala, eds. Careful eating: bodies, food and care. Farnham: Ashgate.

Eli, K., Dolan, C., Schneider, T., \& Ulijaszek, S. (2016). Mobile activism, material imaginings, and the ethics of the edible: Framing political engagement through the Buycott app. Geoforum, 74, 63-73.

Foodwatch. (2016). About foodwatch. < https://www.foodwatch.org/en/about-foodwatch/> (accessed 8 August 2016). 
Fox, N. J. (2015). Personal health technologies, micropolitics and resistance: a new materialist analysis. Health 1363459315590248.

Gabriel, Y., \& Lang, T. (2015). The unmanageable consumer. Sage.

Goodman, D., \& Goodman, M. K. (2009). Food networks, alternative. In Kitchin, R. and Thrift, N., eds in chief, International Encyclopedia of Human Geography. Elsevier, 208-220.

Langlois, G., Elmer, G., McKelvey, F., \& Devereaux, Z. (2009). Networked publics: The double articulation of code and politics on Facebook. Canadian Journal of Communication, 34(3).

Law, J., \& Singleton, V. (2013). ANT and politics: Working in and on the world. Qualitative Sociology, 36(4), 485-502.

Lekakis, E. J. (2014). ICTs and ethical consumption: The political and market futures of fair trade. Futures, 62, 164-172.

Lockie, S. (2006). Networks of Agri-Environmental Action: Temporality, Spatiality and Identity in Agricultural Environments. Sociologia Ruralis, 46(1), 22-39.

Morris, C., \& Kirwan, J. (2011). Ecological embeddedness: An interrogation and refinement of the concept within the context of alternative food networks in the UK. Journal of Rural Studies, 27(3), 322-330.

O'Connor, C. (2013). New app lets you boycott Koch Brothers, Monsanto and more by scanning your shopping cart. Forbes, 14 May 2013.

<http://www.forbes.com/sites/clareoconnor/2013/05/14/new-app-lets-you-boycott-kochbrothers-monsanto-and-more-by-scanning-your-shopping-cart/\#3263deda2c82>

Roe, E. J. (2006). Things becoming food and the embodied, material practices of an organic food consumer. Sociologia Ruralis, 46(2), 104-121.

Ruppert, E., Law, J., \& Savage, M. (2013). Reassembling social science methods: The challenge of digital devices. Theory, Culture \& Society, 30(4), 22-46.

Sayes, E. (2014). Actor-Network Theory and methodology: Just what does it mean to say that nonhumans have agency?. Social Studies of Science, 44(1), 134-149.

Schneider, T., Eli, K., McLennan, A., Dolan, C., Lezaun, J., \& Ulijaszek, S. (under review).

Siniscalchi, V. and Counihan, C. (2014). Ethnography of food activism. In C. Counihan and V.

Siniscalchi, eds. Food activism: Agency, democracy and economy. London: Bloomsbury, pp. 3-12.

Van Dijck, J., \& Poell, T. (2013). Understanding social media logic. Media and Communication, 1(1), 2-14.

Vegh, S. (2003). Classifying forms of online activism. In M. McCaughey and M. D. Ayers, eds. Cyberactivism: Online activism in theory and practice. London: Routledge, 71-95. 